BMJ Paediatrics Open

\title{
Bronchopulmonary dysplasia - impact of severity and timing of diagnosis on neurodevelopment of preterm infants: a retrospective cohort study
}

Anna Maria Malavolti, ${ }^{1,2}$ Dirk Bassler, ${ }^{1}$ Romaine Arlettaz-Mieth, ${ }^{1}$ Giacomo Faldella, ${ }^{2}$ Beatrice Latal, ${ }^{3}$ Giancarlo Natalucci ${ }^{1,3}$

\section{ABSTRACT}

To cite: Malavolti AM Bassler D, Arlettaz-Mieth R, et al. Bronchopulmonary dysplasia-impact of severity and timing of diagnosis on neurodevelopment of preterm infants: a retrospective cohort study. BMJ Paediatrics Open 2018;2:e000165. doi:10.1136/ bmjpo-2017-000165

- Additional material is published online only. To view, please visit the journal online (http://dx.doi.org/10.1136/ bmjpo-2017-000165).

Received 20 June 2017 Revised 20 November 2017 Accepted 12 December 2017

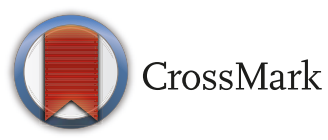

${ }^{1}$ Department of Neonatology, University of Zurich and Zurich University Hospital, Zurich, Switzerland

${ }^{2}$ Department of Gynaecological, Obstetric and Paediatric Sciences, University Hospital of Bologna, Bologna, Italy ${ }^{3}$ Child Development Centre, Zurich University Children's Hospital, Zurich, Switzerland

Correspondence to Dr Giancarlo Natalucci; giancarlo.natalucci@usz.ch infants.
Objective To assess the contribution of the severity of bronchopulmonary dysplasia (BPD) and the time point of its diagnosis to the prediction of neurodevelopmental impairment (NDI) at corrected age of 2 years in preterm

Design Retrospective cohort study.

Setting Level-III perinatal centre.

Patients and outcome measures Infants born in 2000-2013 with gestational age $<30$ weeks. BPD was defined as $\mathrm{FiO}_{2}>21 \%$ for $\geq 28$ days and its severity classified as mild, $\mathrm{FiO}_{2}=21 \%$; moderate, $\mathrm{FiO}_{2}<30 \%$ and severe, $\mathrm{FiO}_{2} \geq 30 \%$ and/or positive pressure support. We applied these criteria at two time points: 36 and 40 weeks' postmenstrual age (PMA). Multivariable regression models were used to estimate the association $(0 \mathrm{R}(95 \% \mathrm{Cl}))$ between BPD characteristics and NDI defined as cognitive or motor development score <2 SD; severe cerebral palsy; deafness and blindness.

Results of 610 ( $81 \%$ of cohort) children assessed at 2 years, 357 (58\%) had BPD and 98 (16\%) had NDI. Neither $\mathrm{FiO}_{2}>21 \%$ for $\geq 28$ days nor mild or moderate BPD at either 36 or 40 weeks' PMA was associated with NDI, but severe BPD was (at 36 weeks' PMA 5.6 (2.0 to 16.0) and at 40 weeks' PMA 16.6 (4.6 to 59.9)). Infants with severe BPD at both 36 and 40 weeks' PMA had lower mental (mean difference $-11.4(-18.5$ to -4.3$),-25.7(-35.9$ to $-15.5)$, respectively) and motor $(-7.8(-14.9$ to -0.6$)$, $-20.1(-30.7$ to -9.5$)$, respectively), developmental scores than infants without BPD.

Conclusion In this cohort, severe BPD was a better independent predictor of NDI at 2 years than mild or moderate BPD. BPD diagnosed at 40 weeks' PMA might allow better identification of infants at highest risk for NDI.

\section{INTRODUCTION}

Since its first description in $1967,{ }^{1}$ many groups have used alternative definitions of bronchopulmonary dysplasia (BPD) to describe this chronic lung disorder, which primarily affects very low birthweight infants. Recent evidence suggests that lung dysmaturation is a key determinant of the development of this condition of the lungs seen

\section{What is already known on this topic?}

Bronchopulmonary dysplasia (BPD) is a chronic lung disorder that primarily affects the very low birthweight infant.

- The current 2000-National Institute of Child Health and Human Development consensus definition of BPD allows prediction of abnormal pulmonary outcome and somatic growth at 2 years of age. BPD is defined heterogeneously in the literature.

\section{What this study hopes to add?}

- Among all forms of bronchopulmonary dysplasia (BPD), severe BPD provides the best prediction of neurodevelopmental impairment (NDI) at 2 years of corrected age.

- The assessment of BPD at 40 weeks postmenstrual age (PMA) might allow better identification of infants at high risk for NDI than assessment at 36 weeks' PMA.

in extremely premature infants with BPD. ${ }^{2}$ The need to quantify BPD severity to enable prediction of respiratory outcome for these infants led the National Institute of Child Health and Human Development (NICHD) workshop to introduce a classification in $2000 .^{3}$ This definition allows the severity of the disease to be classified by oxygen dependency and respiratory support at 36 weeks' postmenstrual age (PMA) into mild, moderate and severe forms. Independent of any histopathological correlate, this clinical definition has proved useful in the prediction of abnormal pulmonary outcome and somatic growth at 2 years of age. ${ }^{45}$ Subsequent studies have adopted this classification to describe neurodevelopmental outcome of infants with BPD, but it remains unclear whether BPD severity assessment at 36 weeks' PMA also provides the best 
timing of assessment for the prediction of neurological outcome. ${ }^{4-9}$ In fact, despite the 2000-NICHD consensus, BPD is defined heterogeneously in the literature, and studies describing neurodevelopmental outcome after BPD report controversial results. ${ }^{10-12}$ This study aimed to assess the contribution of the severity of BPD and the time point of its diagnosis to the prediction of neurodevelopmental impairment (NDI) at corrected age of 2 years in preterm infants. We hypothesised that BPD severity is an independent risk factor for NDI and that, among all criteria, the presence of persistent severe BPD at term-equivalent age is the best predictor of subsequent neurodevelopmental outcome.

\section{METHODS}

Study subjects

This is a retrospective cohort study that examined very premature liveborn infants with $<30$ weeks of gestation at the Zurich University Hospital, a tertiary perinatal centre, from 1 January 2000 to 31 December 2013. Exclusion criteria were a priori palliative care in delivery room, major congenital anomalies (ie, genetic anomaly, syndrome or malformation of a major organ system); dead before hospital discharge; transfer to another centre within the first day of life and insufficient documentation. We extracted neonatal and follow-up data from the prospective national database of the Swiss Neonatal Network. Specific information concerning the severity of BPD according to the 2000-NICHD consensus ${ }^{3}$ at 36 and 40 weeks' PMA was extracted from the neonatal charts.

\section{Neonatal data}

BPD was defined as oxygen supplementation for $\geq 28$ days of life. ${ }^{3}$ BPD severity was scored at 36 weeks' PMA according to the 2000-NICHD consensus ${ }^{3}$ as mild BPD (no oxygen supplementation), moderate BPD (oxygen supplementation $<30 \%$ ) or severe BPD (oxygen supplementation $\geq 30 \%$ and/or requirement for positive pressure support). BPD severity was also scored at 40 weeks' PMA by the same criteria. Gestational age was defined by the best estimate available from prenatal ultrasound findings or obstetric measurements based on the last menstrual period. Birthweight z-scores were calculated based on growth curves by Voigt et al. ${ }^{13}$ Major brain lesions were defined as intraventricular haemorrhage >grade 2 or cystic periventricular leukomalacia on ultrasound examination according to Volpe's ${ }^{14}$ and de Vries et $a l{ }^{15}{ }^{15}$ classifications, respectively. Persistent ductus arteriosus was defined as a ductus arteriosus requiring medical or surgical closure. Retinopathy of prematurity, necrotising enterocolitis and neonatal sepsis were defined as previously published. ${ }^{8}$ Socioeconomic status was estimated by a validated 12-point socioeconomic scale based on maternal education and paternal occupation, on which high scores represent low socioeconomic class.

\section{Neurodevelopmental outcome at 2 years of age}

Children were invited to a follow-up at the corrected age of 18-24 months in the Child Development Centre of the University Children's Hospital Zurich, where experienced developmental paediatricians performed a structured neurological examination and a developmental assessment. Following the recommendation of the Swiss Neonatal Network, the follow-up examinations were based on the Bayley Scales of Infant Development, Second Edition, from 2000 to 2013 (BSID-II) ${ }^{16}$ and then on the Bayley Scales of Infant and Toddler Development, Third Edition (Bayley-III).$^{17}$ The Griffiths Mental Development Scales-Revised (GMDS) ${ }^{18}$ were used for a few children early in the study. Children with significant disability precluding completion of the development test were assigned a development score of 1 below -3 SD. Cerebral palsy was defined according to Rosenbaum et $a l^{19}$ and was graded according to the Gross Motor Function Classification System (GMFCS) for children aged $\leq 2$ years. ${ }^{20}$ Vision and hearing were assessed by either direct examination or caregiver report. NDI was defined as one of following: mental or motor development index below 70 (-2SD) on the BSID-II; cognitive or motor composite score below 85 (see below) on the Bayley-III; a global score on the GMDS below $76(-2 \mathrm{SD})$; cerebral palsy with GMFCS above 1; the absence of useful hearing even with aids; blindness or only perception of light. According to recent literature, ${ }^{21-23}$ Bayley-III scores below 85 were considered as equivalent to indices below $70(-2 \mathrm{SD})$ in the BSID-II.

\section{Statistics}

$\chi^{2}$ (or Fisher's exact test), independent t-test and MannWhitney $\mathrm{U}$ tests were used to compare baseline characteristics between infants with and without BPD. Multivariable regression models were used to compare outcome measures between infants without BPD (reference) and (1) infants with BPD, as defined as oxygen supplementation for $\geq 28$ days; (2) infants with mild, moderate and severe BPD, defined at 36 weeks' PMA and (3) infants with mild, moderate and severe BPD at 40 weeks' PMA. We adjusted models for variables that were significantly unequally distributed among groups (see the Results section). Two post hoc analyses were performed by adjusting the models to include known neonatal predictors of poor neurodevelopment (ie, gestational age, sex, necrotising enterocolitis, retinopathy of prematurity, major brain lesions, sepsis and socioeconomic status) in accordance with previous reports ${ }^{8}$ and by excluding children assessed with Bayley-III and GMDS. Associations are given as ORs and mean differences (MDs) with $95 \%$ CI. In order to estimate the calibration and discrimination of the regression models, we applied the Hosmer and Lemeshow test and calculated the area under the receiver operating curve, respectively. Finally, we calculated accuracy, sensitivity, specificity and positive and negative predictive values for NDI of (1) BPD, (2) BPD severity at 36 weeks' PMA and (3) BPD severity at 40 weeks' PMA, using the group of infants without BPD as reference. We did not 


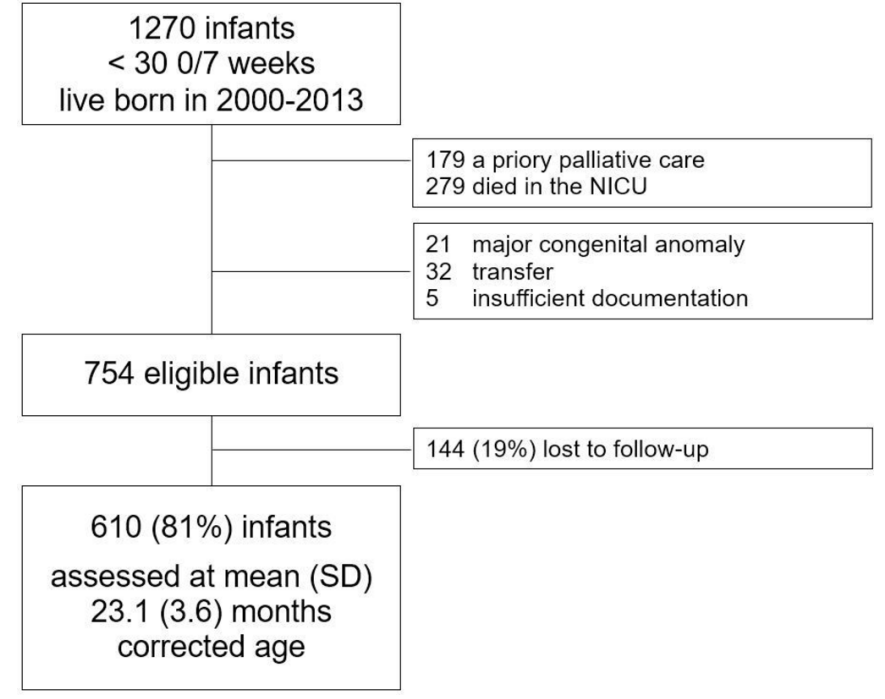

Figure 1 Study flow chart. NICU, neonatal intensive care unit.

impute missing values, because only $4.1 \%$ of observations were unavailable. SPSS V.21.0 (IBM) was used. Probability values below 0.05 were considered significant, and testing was two-sided.
The study centre was obliged to inform parents about the scientific use of anonymised data.

\section{RESULTS}

\section{Study subjects and neonatal data}

Among 1270 liveborn infants registered during the study period, 516 infants were excluded because of death before discharge $(n=279)$, a priori palliative care in delivery room $(n=179$ : with gestational age $22(n=12)$, $23(\mathrm{n}=69)$ and $24(\mathrm{n}=70)$ weeks, and major congenital anomaly $(n=28))$ transfer to another hospital $(n=32)$, major congenital anomalies $(\mathrm{n}=21)$ or insufficient neonatal documentation $(\mathrm{n}=5)$. Among the 754 eligible infants, $610(81 \%)$ returned for follow-up (figure 1): $303(50 \%)$ females, mean (SD, range) gestational age 27.9 (1.2, 24.4-29.9) weeks and birth weight 1050 (230, 400-1750) g. Infants lost to follow-up had a higher gestational age and higher birth weight (both $\mathrm{P}<0.001$ ), and a lower rate of BPD ( $45 \%$ vs $58 \%, \mathrm{P}=0.007)$ than those examined. In the 610 infants examined, BPD was diagnosed in $357(58 \%)$. In comparison to infants without BPD, infants with BPD presented significant differences (table 1): lower gestational age and birthweight z-score,

Table 1 Comparison of baseline and neonatal characteristics of infants with and without BPD

\begin{tabular}{|c|c|c|c|c|}
\hline & $\begin{array}{l}\text { All infants } \mathrm{n}=610 \\
\mathrm{n}(\%) \\
\text { Mean (SD) }\end{array}$ & $\begin{array}{l}\text { No BPD n=253 } \\
n(\%) \\
\text { Mean (SD) }\end{array}$ & $\begin{array}{l}\text { BPD } n=357 \\
n(\%) \\
\text { Mean (SD) }\end{array}$ & P value* \\
\hline Outborn & $50(8 \%)$ & $27(11 \%)$ & $23(6 \%)$ & 0.061 \\
\hline Male gender & $307(50 \%)$ & $113(45 \%)$ & $194(54 \%)$ & 0.013 \\
\hline Gestational age (weeks) & $27.9(1.37)$ & $28.5(1.13)$ & $27.4(1.32)$ & $<0.001$ \\
\hline Birth weight (gram) & $1030(250)$ & $1.130(242)$ & 965 (226) & $<0.001$ \\
\hline z-score & $0.27(0.85)$ & $0.43(0.80)$ & $-0.13(0.85)$ & 0.015 \\
\hline Small for gestational age $\dagger$ & $53(9 \%)$ & $21(8 \%)$ & $32(9 \%)$ & 0.753 \\
\hline Singleton & $168(27 \%)$ & $64(26 \%)$ & $104(30 \%)$ & 0.269 \\
\hline Antenatal corticosteroids (completed) & $442(72 \%)$ & $181(71 \%)$ & $261(73 \%)$ & 0.669 \\
\hline Chorioamnionitis & $143(23 \%)$ & $59(25 \%)$ & $84(24 \%)$ & 0.866 \\
\hline Caesarean delivery & $507(83 \%)$ & $205(81 \%)$ & $302(84 \%)$ & 0.247 \\
\hline Umbilical artery $\mathrm{pH}$ & $7.31(0.09)$ & $7.31(0.08)$ & $7.31(0.09)$ & 0.874 \\
\hline Days of mechanical ventilation & $3.4(6.2)$ & $1.3(3.3)$ & $3.5(7.2)$ & 0.001 \\
\hline Surfactant & $267(44 \%)$ & $76(30 \%)$ & $191(53 \%)$ & $<0.001$ \\
\hline Intraventricular haemorrhage $>$ grade 2 & $44(7 \%)$ & $10(4 \%)$ & $34(9 \%)$ & 0.009 \\
\hline Cystic periventricular leukomalacia & $6(1 \%)$ & $4(2 \%)$ & $2(1 \%)$ & 0.206 \\
\hline Retinopathy of prematurity $>$ grade 2 & $10(2 \%)$ & $6(2 \%)$ & $14(4 \%)$ & 0.315 \\
\hline Sepsis & $115(19 \%)$ & $25(10 \%)$ & $90(25 \%)$ & $<0.001$ \\
\hline Necrotising enterocolitis & $22(4 \%)$ & $10(4 \%)$ & $12(3 \%)$ & 0.700 \\
\hline Persistent ductus arteriosus & $319(52 \%)$ & 99 (39\%) & $220(62 \%)$ & $<0.001$ \\
\hline Socioeconomic score & $5.9(2.5)$ & $5.9(2.5)$ & $5.8(2.5)$ & 0.921 \\
\hline
\end{tabular}

${ }^{*}$ Comparison between infants with and without BPD: Pearson's $\chi^{2}$ (or Fisher exact) test (for dichotomous variables) and independent t-test and Mann-Whitney U tests (for linear variables).

†Birth weight $<10$ th percentile.

BPD, bronchopulmonary dysplasia. 
longer mechanical ventilation time and a higher rate of male sex, surfactant treatment, intraventricular haemorrhage higher than grade 2, sepsis and persistent ductus arteriosus. At 36 weeks' PMA, BPD was classified as mild in $35 \%$, moderate in $15 \%$ and severe in $8 \%$ of cases, while at 40 weeks' PMA in $50 \%, 4 \%$ and $3.7 \%$ of cases, respectively. Three infants with severe BPD at 36 weeks' PMA but insufficient data at 40 weeks' PMA needed $22 \%$ to $29 \%$ oxygen at discharge from hospital.

\section{Neurodevelopmental outcome at 2 years of age}

Follow-up assessment was performed at a mean (SD, range) corrected age of 23.1 (3.6, 16.5-37.6) months: body weight $11.7(1.8,8.0-20.0) \mathrm{kg}$, length 85.6 (5.2, $68.0-100.0) \mathrm{cm}$. There was no difference in the mean age at follow-up between infants with (23.1 (3.4)) and without (23.2 (3.8)) BPD ( $\mathrm{P}=0.770)$. Of 610 examined children, $460(75 \%), 109(18 \%)$ and $20(3 \%)$ children were assessed with the Bayley-II, Bayley-III and GMDS, respectively, while in 21 (4\%) children, only part of a developmental assessment could be performed. Ninety-eight (16\%) children suffered from NDI. Mean (SD) mental and motor development indices of Bayley-II were 88 (14) and 85 (17), respectively; mean cognitive and motor scores of Bayley-III were 99 (15) and 95 (14), respectively; mean general quotient of GMDS was 86 (14). None of the three children without sufficient data for scoring BPD severity at 40 weeks' PMA had NDI.

Association between BPD and its severity defined at 36 and at 40 weeks' PMA and NDI

Multivariable logistic regression (adjusted for gestational age, sex, birthweight z-score, intraventricular haemorrhage > grade 2, persistent ductus arteriosus, days of mechanical ventilation, surfactant and sepsis) showed that severe BPD was positively associated with NDI at age 2 years (OR $(95 \% \mathrm{CI})$ at 36 weeks' PMA: 5.6 (2.0 to 16.0) and at 40 weeks' PMA: 16.6 (4.6 to 59.9), respectively) (table 2A-C). However, BPD (need for oxygen supplementation for $\geq 28$ days of life) and mild and moderate BPD at 36 and 40 weeks' PMA were not. Sensitivity analyses revealed similar results after adjusting for known neonatal risk factors for poor neurodevelopment (online supplementary table A) and after exclusion of children tested with the Bayley-III and GMDS (online supplementary table B). The full results of the multivariate models analysing the relationship between BPD and NDI are presented in an online supplementary table D.

Mental and psychomotor development indices (BSIDII) of children with severe BPD were lower than those of

Table 2 Multivariable association of (A) BPD, defined as oxygen supplementation for $\geq 28$ days of life, and its severity defined at (B) 36 weeks' PMA and (C) 40 weeks' PMA with NDI at mean (SD) corrected age 23.1 (3.6) months

(A) BPD

\begin{tabular}{|c|c|c|c|c|c|c|c|c|c|c|}
\hline & & \multicolumn{3}{|c|}{ No BPD (reference) $n=253$} & \multicolumn{2}{|c|}{$\begin{array}{l}\text { BPD } \\
n=357\end{array}$} & \multicolumn{2}{|c|}{ OR $(95 \% \mathrm{Cl})$} & \multicolumn{2}{|l|}{$P$ value } \\
\hline \multicolumn{2}{|l|}{ NDI, n (\%) } & \multicolumn{2}{|l|}{$32(13)$} & \multicolumn{2}{|c|}{$66(18)$} & \multicolumn{3}{|c|}{1.5 (0.8 to 2.5$)$} & \multicolumn{2}{|l|}{0.180} \\
\hline \multicolumn{2}{|c|}{ Cerebral palsy, n (\%) } & \multicolumn{2}{|l|}{$9(3)$} & \multicolumn{2}{|c|}{$5(1.4)$} & \multicolumn{3}{|c|}{0.4 (0.0 to 2.4$)$} & \multicolumn{2}{|l|}{0.332} \\
\hline \multicolumn{2}{|c|}{ Deafness, n (\%) } & \multicolumn{2}{|l|}{$2(0.8)$} & \multicolumn{2}{|c|}{$3(0.8)$} & \multicolumn{3}{|c|}{0.5 (0.0 to 3.7$)$} & \multicolumn{2}{|l|}{0.522} \\
\hline \multicolumn{2}{|c|}{ Blindness, n (\%) } & \multicolumn{2}{|l|}{0} & \multicolumn{2}{|c|}{$2(0.6)$} & \multicolumn{2}{|c|}{-} & & \multicolumn{2}{|l|}{ NA } \\
\hline \multicolumn{11}{|c|}{ (B) 36 weeks' PMA } \\
\hline NDI, n (\%) & $32(13)$ & $29(13)$ & 1.1 (0.6 to 2.1$)$ & 0.722 & $21(23)$ & $1.5(0.7$ to 3.4$)$ & 0.324 & $16(31)$ & $5.6(2.0$ to 15.9$)$ & 0.001 \\
\hline $\begin{array}{l}\text { Cerebral } \\
\text { palsy, } n(\%)\end{array}$ & $9(3)$ & $3(1)$ & $0.6(0.1$ to 4.9$)$ & 0.680 & $2(2)$ & 0.4 (0.0 to 5.2$)$ & 0.482 & 0 & - & NA \\
\hline $\begin{array}{l}\text { Deafness, } n \\
\text { (\%) }\end{array}$ & $2(0.8)$ & $1(0.5)$ & 0.2 (0.0 to 2.9$)$ & 0.240 & 0 & - & NA & $2(4)$ & $2.0(0.2$ to 25.0$)$ & 0.568 \\
\hline & $\begin{array}{l}\text { No BPD } \\
\text { (reference) } \\
n=253\end{array}$ & $\begin{array}{l}\text { Mild BPD at } \\
40 \text { PMA } \\
n=304\end{array}$ & OR $(95 \% \mathrm{Cl})$ & $P$ value & $\begin{array}{l}\text { Moderate } \\
\text { BPD at } 40 \\
\text { PMA } n=27\end{array}$ & OR $(95 \% \mathrm{Cl})$ & $P$ value & $\begin{array}{l}\text { Severe } \\
\text { BPD at } 40 \\
\text { PMA } n=23\end{array}$ & OR (95\% Cl) & $P$ value \\
\hline NDI, n (\%) & $32(13)$ & $46(15)$ & $1.2(0.6$ to 2.1$)$ & 0.599 & $6(22)$ & 2.2 (0.6 to 8.1$)$ & 0.213 & $14(61)$ & 16.6 (4.6 to 59.9$)$ & $<0.001$ \\
\hline $\begin{array}{l}\text { Cerebral } \\
\text { palsy, } \mathrm{n}(\%)\end{array}$ & $9(3)$ & $5(2)$ & 0.4 (0.1 to 2.5$)$ & 0.373 & 0 & - & NA & 0 & - & NA \\
\hline $\begin{array}{l}\text { Deafness, } \\
\mathrm{n}(\%)\end{array}$ & $2(0.8)$ & $1(0)$ & 0.1 (0.0 to 1.9$)$ & 0.126 & 1 (4) & $1.5(0.0$ to 34.1$)$ & 0.792 & $1(4)$ & $0.8(0.0$ to 27.3$)$ & 0.933 \\
\hline $\begin{array}{l}\text { Blindness, } \\
\mathrm{n}(\%)\end{array}$ & 0 & $2(1)$ & - & NA & 0 & - & NA & 0 & - & NA \\
\hline
\end{tabular}

BPD, bronchopulmonary dysplasia; NA, not applicable; NDI, neurodevelopmental impairment; PMA, postmenstrual age. 
Table 3 Predictive values $(95 \% \mathrm{Cl})$ of BPD for neurodevelopmental impairment at mean (SD) corrected age 23.1 (3.6) months

\begin{tabular}{|c|c|c|c|c|c|c|c|}
\hline & BPD & $\begin{array}{l}\text { Mild BPD at } \\
36 \text { PMA }\end{array}$ & $\begin{array}{l}\text { Moderate } \\
\text { BPD at } 36 \\
\text { PMA }\end{array}$ & $\begin{array}{l}\text { Severe BPD } \\
\text { at } 36 \text { PMA }\end{array}$ & $\begin{array}{l}\text { Mild BPD at } \\
40 \text { PMA }\end{array}$ & $\begin{array}{l}\text { Moderate BPD } \\
\text { at } 40 \text { PMA }\end{array}$ & $\begin{array}{l}\text { Severe BPD } \\
\text { at } 40 \text { PMA }\end{array}$ \\
\hline Sensitivity & $\begin{array}{l}67 \% \\
\text { (57\% to } 76 \%)\end{array}$ & $\begin{array}{l}47 \% \\
\text { (35\% to } 61 \%)\end{array}$ & $\begin{array}{l}40 \% \\
\text { (26\% to } 54 \%)\end{array}$ & $\begin{array}{l}33 \% \\
(20 \% \text { to } 48 \%)\end{array}$ & $\begin{array}{l}59 \% \\
\text { (47\% to } 70 \%)\end{array}$ & $\begin{array}{l}16 \% \\
(6 \% \text { to } 31 \%)\end{array}$ & $\begin{array}{l}30 \% \\
(18 \% \text { to } 46 \%)\end{array}$ \\
\hline Specificity & $\begin{array}{l}43 \% \\
(39 \% \text { to } 48 \%)\end{array}$ & $\begin{array}{l}54 \% \\
(49 \% \text { to } 59 \%)\end{array}$ & $\begin{array}{l}76 \% \\
(71 \% \text { to } 81 \%)\end{array}$ & $\begin{array}{l}86 \% \\
(81 \% \text { to } 90 \%)\end{array}$ & $\begin{array}{l}46 \% \\
(42 \% \text { to } 50 \%)\end{array}$ & $\begin{array}{l}91 \% \\
(87 \% \text { to } 94 \%)\end{array}$ & $\begin{array}{l}96 \% \\
(93 \% \text { to } 98 \%)\end{array}$ \\
\hline $\begin{array}{l}\text { Negative } \\
\text { predictive value }\end{array}$ & $\begin{array}{l}87 \% \\
(84 \% \text { to } 90 \%)\end{array}$ & $\begin{array}{l}87 \% \\
(84 \% \text { to } 90 \%)\end{array}$ & $\begin{array}{l}87 \% \\
(85 \% \text { to } 89 \%)\end{array}$ & $\begin{array}{l}87 \% \\
(85 \% \text { to } 89 \%)\end{array}$ & $\begin{array}{l}87 \% \\
(84 \% \text { to } 90 \%)\end{array}$ & $\begin{array}{l}87 \% \\
(86 \% \text { to } 89 \%)\end{array}$ & $\begin{array}{l}87 \% \\
(85 \% \text { to } 89 \%)\end{array}$ \\
\hline Accuracy & $47 \%$ & $53 \%$ & $70 \%$ & $78 \%$ & $48 \%$ & $81 \%$ & $85 \%$ \\
\hline
\end{tabular}

The predictive values of each form of BPD (BPD, mild, moderate, severe) have been calculated with 'No BPD' as reference. BPD, bronchopulmonary dysplasia; PMA, postmenstrual age.

children without BPD when severity was assessed at 36 and at 40 weeks' PMA (mean NDI difference -11.4

$(-18.5$ to -4.2$)$ and $-26.0(-36.0$ to -15.5$)$ and mean PDI difference $-7.8(-14.9$ to -0.6$)$ and $-20.1(-30.7$ to -9.5 ), respectively) (online supplementary table C1). BPD was not associated with Bayley-III (online supplementary table C2), rate of cerebral palsy or severe vision or hearing problems.

Among all BPD definition criteria, severe BPD at 40 weeks' PMA provided the highest specificity (96\%), positive $(61 \%)$ and negative $(87 \%)$ predictive values, and accuracy $(85 \%)$ for the prediction of NDI at the time of follow-up, while oxygen supplementation for $\geq 28$ days of life or at 36 weeks' PMA provided the best sensitivity $(67 \%)$ (table 3$)$.

\section{DISCUSSION}

This retrospective study aimed to gauge the extent to which the severity of BPD and the time of its diagnosis may be used to optimise the prediction of neurological development at the corrected age of 2 years in preterm infants $<30$ weeks of gestation. The main findings show that, among all forms of BPD, severe BPD provides the best prediction of NDI and that the assessment of BPD at 40 weeks' PMA seems to better predict NDI than at 36 weeks' PMA. These two main observations are suggestive to confirm our hypothesis, and although they do not definitively prove it, they raise the question whether the time point for the 2000-NICHD ${ }^{3}$ severity-based assessment of BPD at 36 weeks' PMA might be redefined to improve prognosis.

Few studies, including the present one, have adopted the severity-based 2000-NICHD consensus definition of $\mathrm{BPD}^{3}$ to predict neurodevelopmental outcome. As recently reported, a diverse range of definitions of BPD can be found in the literature. ${ }^{24}$ A binary definition of BPD appears less informative for the prognosis of neurodevelopmental outcome than a severity-based definition. The current severity-based definition of BPD was first introduced as a practical tool to predict the severity of lung damage, and 36 weeks' PMA was identified as the best time point to assess severity for the purpose of predicting respiratory outcome. ${ }^{25}$ However, it remains unclear what roles the severity of BPD and the timing of the diagnosis play in the prediction of neurological development.

The present findings are in agreement with recent literature $^{26}$ demonstrating that oxygen supplementation and respiratory support at 40 weeks' PMA are a better predictor of neurosensory morbidity at 18-24 months. A severity-based assessment of BPD of preterm infants at 40 weeks' PMA should be feasible in an outpatient setting, as preterm infants have often already been discharged from hospital by then.

The BPD incidence observed in our cohort seems to be slightly higher than that reported in the literature concerning infants born $<30$ weeks of gestation. ${ }^{24} 27$ This might be explained by a bias in the selection of the study subjects; in addition, clinicians' subjective judgements might have influenced the classification of BPD, especially its mild and moderate forms. ${ }^{28}$ The increase of about one-third in the number of infants with mild BPD between 36 and 40 weeks' PMA corroborates this latter interpretation. A more objective approach to BPD classification might have been provided by a room air test to identify the objective need of an infant for supplemental respiratory support to reach $90 \%$ of oxygen saturation at a definite PMA. However, our dataset did not reliably provide this information.

The negative association between BPD and NDI strengthened substantially when infants were diagnosed with severe BPD between 36 and 40 weeks' PMA. This provided a higher NDI MD, from 0.8 to $1.7 \mathrm{SD}$, than for infants without BPD. Similar observations have been reported previously ${ }^{10}{ }^{12}$ but have not exhibited similar impact. The lack of association between BPD and the developmental scores of the Bayley-III may be explained by the small subgroup's size reducing the power of analysis. In our study, the number of children affected by cerebral palsy, severe hearing and visual disability was not sufficient to draw any conclusion on a possible association between BPD and these morbidities. 
Strength of this study is the size of the cohort, although the low prevalence of the severe forms of BPD implies wide CIs and high value of negative predictive value. Further study strengths are the prospective systematic data records concerning neonatal and neurodevelopmental variables, and the adjustment of the analyses for several confounding factors. The rate of infants lost to follow-up of $19 \%$ represents a limitation of the study. As gestational age and BPD rate were lower and higher, respectively, in infants visited at 2 years of corrected age than in those lost to follow-up, we might assume that we assessed a population sample with high neurodevelopmental risk. The other main study limitations are the retrospective approach, in which specific characteristics of the neonatal respiratory course of the study infants have been extracted from their clinical charts; the lack of information concerning a room air test for the classification of BPD severity; and the fact that the indication for respiratory support might have been influenced by a subjective judgement of the clinicians in charge.

These limitations might have introduced an information bias, especially within the group of infants with moderate BPD, among whom we observed the largest number of reclassifications to mild BPD between 36 and 40 weeks' PMA. The inclusion of the various developmental tests used within this cohort represents another important limitation, because it might have introduced a bias in the classification of outcomes. However, the sensitivity analysis that focused purely on infants tested with Bayley-II (the largest group of infants within the cohort) supports the study conclusions.

Finally, as no local normative data for Bayley-III is available in Switzerland yet, we opted to set the cut-off for NDI at development scores below 85 and not below 70 for this test version. Despite recent literature ${ }^{21-23}$ in support of this choice, we cannot prove the assumption that Bayley-III tended to overestimate development in this cohort.

In conclusion, we found that, in this cohort, severe BPD was a better independent predictor of NDI at the age of 2 years than mild or moderate BPD. The diagnosis of severe BPD at 40 weeks' PMA seems to allow better identification of infants at high risk of poor neurodevelopment than at 36 weeks' PMA. As the generalisability of the present findings is reduced by the study limitations, further prospective studies are needed to confirm them. In addition to the present findings, respiratory outcome data are needed to support resetting the BPD definition so as to provide higher prognostic value than the current consensus.

Acknowledgements We gratefully thank all children and their parents who participated in this study.

Contributors AMM and GN were involved in the study design, data acquisition, analysis and interpretation, and writing of the manuscript. DB was involved in the study design, data interpretation and manuscript reviewing. RA-M, GF and BL were involved in the data acquisition and interpretation, and manuscript reviewing. All authors reviewed and approved the final draft.

Funding GN was supported by the From the Swiss National Science Foundation (grant number PZOOP3_161146).

Competing interests None declared.
Ethics approval Data collection and evaluation for this study were approved by the institutional ethical review boards and by the Swiss Federal Commission for Privacy Protection in Medical Research.

Provenance and peer review Not commissioned; externally peer reviewed.

Open Access This is an Open Access article distributed in accordance with the Creative Commons Attribution Non Commercial (CC BY-NC 4.0) license, which permits others to distribute, remix, adapt, build upon this work non-commercially, and license their derivative works on different terms, provided the original work is properly cited and the use is non-commercial. See: http://creativecommons.org/ licenses/by-nc/4.0/

(C) Article author(s) (or their employer(s) unless otherwise stated in the text of the article) 2018. All rights reserved. No commercial use is permitted unless otherwise expressly granted.

\section{REFERENCES}

1. Northway WH, Rosan RC, Porter DY. Pulmonary disease following respirator therapy of hyaline-membrane disease. Bronchopulmonary dysplasia. N Engl J Med 1967;276:357-68.

2. Day CL, Ryan RM. Bronchopulmonary dysplasia: new becomes old again!. Pediatr Res 2017;81:210-3.

3. Jobe AH, Bancalari E. Bronchopulmonary dysplasia. Am J Respir Crit Care Med 2001;163:1723-9.

4. Ehrenkranz RA, Walsh MC, Vohr BR, et al. Validation of the National Institutes of Health consensus definition of bronchopulmonary dysplasia. Pediatrics 2005;116:1353-60.

5. Jeng SF, Hsu CH, Tsao PN, et al. Bronchopulmonary dysplasia predicts adverse developmental and clinical outcomes in very-lowbirthweight infants. Dev Med Child Neurol 2008;50:51-7.

6. Schmidt B, Asztalos EV, Roberts RS, et al. Impact of bronchopulmonary dysplasia, brain injury, and severe retinopathy on the outcome of extremely low-birth-weight infants at 18 months: results from the trial of indomethacin prophylaxis in preterms. JAMA 2003;289:1124-9.

7. Karagianni P, Tsakalidis C, Kyriakidou M, et al. Neuromotor outcomes in infants with bronchopulmonary dysplasia. Pediatr Neurol 2011;44:40-6.

8. Schlapbach LJ, Adams M, Proietti E, et al. Outcome at two years of age in a Swiss national cohort of extremely preterm infants born between 2000 and 2008. BMC Pediatr 2012;12:198.

9. Synnes A, Luu TM, Moddemann D, et al. Determinants of developmental outcomes in a very preterm Canadian cohort. Arch Dis Child Fetal Neonatal Ed 2017;102:F235-F234.

10. Hintz SR, Kendrick DE, Vohr BR, et al. Changes in neurodevelopmental outcomes at 18 to 22 months' corrected age among infants of less than 25 weeks'gestational age born in 19931999. Pediatrics 2005;115:1645-51

11. Laughon M, O'Shea MT, Allred EN, et al. Chronic lung disease and developmental delay at 2 years of age in children born before 28 weeks' gestation. Pediatrics 2009;124:637-48.

12. Natarajan G, Pappas A, Shankaran S, et al. Outcomes of extremely low birth weight infants with bronchopulmonary dysplasia: impact of the physiologic definition. Early Hum Dev 2012;88:509-15

13. Voigt $\mathrm{M}$, Fusch $\mathrm{C}, \mathrm{Od} \mathrm{H}$, et al. Analysis of the Neonatal Collective in the Federal Republic of Germany 12th Report: Presentation of Detailed Percentiles for the Body Measurements of Newborns. Geburtsh Frauenheilk 2006;66:956-70.

14. Volpe JJ. Intracranial hemorrhage: germinal matrix hemorrhage. Volpe JJ, ed. Neurology of the newborn. Philadelphia: Saunders Elsevier, 2008:517-288.

15. de Vries LS, Eken P, Dubowitz LM. The spectrum of leukomalacia using cranial ultrasound. Behav Brain Res 1992;49:1-6.

16. Bayley N. Bayley scales of infant development. 2nd edition. San Antonio (TX): The Psychological Corporation, 1993.

17. Bayley N. Bayley scales of infant and toddler development. 3rd ed. San Antonio, TX: Harcourt Assessment, 2006.

18. Griffiths R. The Griffiths mental development scales. Association for research in infant and child development. Henley-on-Thames, UK: The Test Agency, 1996.

19. Rosenbaum $P$, Paneth $N$, Leviton $A$, et al. A report: the definition and classification of cerebral palsy April 2006. Dev Med Child Neurol Suppl. 2007;109:8-14 Erratum in. Dev Med Child Neurol 2007:49:480.

20. Palisano R, Rosenbaum P, Walter S, et al. Development and reliability of a system to classify gross motor function in children with cerebral palsy. Dev Med Child Neurol 1997;39:214-23. 
21. Spittle AJ, Spencer-Smith MM, Eeles AL, et al. Does the Bayley-III Motor Scale at 2 years predict motor outcome at 4 years in very preterm children? Dev Med Child Neurol 2013;55:448-52.

22. Jary S, Whitelaw A, Walløe $L$, et al. Comparison of Bayley-2 and Bayley-3 scores at 18 months in term infants following neonatal encephalopathy and therapeutic hypothermia. Dev Med Child Neurol 2013;55:1053-9.

23. Johnson S, Moore T, Marlow N. Using the Bayley-III to assess neurodevelopmental delay: which cut-off should be used? Pediatr Res 2014;75:670-4.

24. Hines D, Modi N, Lee SK, et al. Scoping review shows wide variation in the definitions of bronchopulmonary dysplasia in preterm infants and calls for a consensus. Acta Paediatr 2017;106:366-74.
25. Shennan AT, Dunn MS, Ohlsson A, et al. Abnormal pulmonary outcomes in premature infants: prediction from oxygen requirement in the neonatal period. Pediatrics 1988;82:527-32.

26. Isayama T, Lee SK, Yang J, et al. Revisiting the Definition of Bronchopulmonary Dysplasia: Effect of Changing Panoply of Respiratory Support for Preterm Neonates. JAMA Pediatr 2017;171:271-9.

27. Ellsbury DL, Acarregui MJ, McGuinness GA, et al. Variability in the use of supplemental oxygen for bronchopulmonary dysplasia. $J$ Pediatr 2002;140:247-9.

28. Bancalari E. Is persistent need for supplemental oxygen a good indicator of adverse pulmonary outcome in very immature infants? Arch Dis Child Fetal Neonatal Ed 2014;99:F254-F255. 